Pat M. Fidopiastis · Daniel J. Bezdek

Michael H. Horn · Judith S. Kandel

\title{
Characterizing the resident, fermentative microbial consortium in the hindgut of the temperate-zone herbivorous fish, Hermosilla azurea (Teleostei: Kyphosidae)
}

\begin{abstract}
The zebraperch, Hermosilla azurea Jenkins and Evermann, a warm-temperate marine fish species with a strictly macroalgal diet, has a relatively long digestive tract with an enlarged hindgut and an associated blind caecum (HC). In zebraperch sampled off Santa Catalina Island, California $\left(33^{\circ} 19^{\prime} 42^{\prime \prime} \mathrm{N}\right.$; $\left.118^{\circ} 18^{\prime} 37^{\prime \prime} \mathrm{W}\right)$ in years 1995 through 2001, direct cell counts, gut epithelium assessment of bacterial attachment, and short-chain fatty acid (SCFA) analyses verified that the zebraperch $\mathrm{HC}$ possesses a dense and morphologically diverse, fermentative microbiota. Bacterial cell counts and morphological diversity were significantly higher in $\mathrm{HC}$ contents compared to anterior gut regions, suggesting that microbial populations were growing along the digestive tract. Similarly, electron micrographs of the $\mathrm{HC}$ epithelium revealed attached microbes, further supporting the possibility that these organisms constitute resident microbiota. Five different SCFAs were detected in all three regions of the digestive tract, but levels were up to three times greater in HC contents. Acetate was consistently the prevailing SCFA in all gut regions. Sequence analysis of bacterial $16 \mathrm{~S}$ rDNA was used to identify predominant bacterial groups in $\mathrm{HC}$ contents. Of the seven main bacterial types identified, Enterovibrio spp. were the dominant bacteria in $\mathrm{HC}$ contents followed by species of Bacteroides,Faecalibacterium, and Desulfovibrio. Taken together, our findings show that the zebraperch $\mathrm{HC}$ harbors a consortium of
\end{abstract}

microbes that appears to assist in the breakdown of algal polysaccharides in the herbivorous diet of the fish.

\section{Introduction}

A diverse microbiota occurs in the digestive tracts of numerous species of herbivorous fishes representing several mainly tropical families (Clements 1991; Clements and Choat 1995; Mountfort et al. 2002). Among these fish families, the Kyphosidae comprises mostly tropical species but also includes the zebraperch Hermosilla azurea Jenkins and Evermann, a strictly herbivorous species that occurs in warm temperate waters of the northeastern Pacific (Sturm and Horn 2001). The high-nutrient assimilation efficiency of the zebraperch (Sturm and Horn 1998) and high levels of fermentation end products in the gut of other kyphosids (Clements and Choat 1997) suggest that microbial fermentation may play an important role in the digestion of algal polysaccharides. The zebraperch intestine is about four times longer than the body and culminates in a highly differentiated hindgut and caecum region (HC; Sturm and Horn 1998). The zebraperch has a relatively long (24-48 h; E.A. Sturm, unpublished data) gut-transit time (cf. Horn 1989) similar to that of Kyphosus cornelii (21 h), another herbivorous kyphosid (Rimmer and Wiebe 1987). A long gut-transit time may allow microbes to ferment algal polysaccharides to completion (Rimmer 1986; Penry and Jumars 1987; Horn 1989). Zebraperch assimilate carbon, nitrogen, and protein from brown seaweeds containing recalcitrant $\beta$-linked polysaccharides and defensive secondary compounds as efficiently as they do from the red and green algal species in their diet, perhaps signifying their tropical ancestry and implying a significant role for gut microbes in their digestive processes (Sturm and Horn 1998).

Reviews by Horn (1989, 1992) and Choat and Clements (1998) suggest that an understanding of the 
taxonomy and biochemistry of gut microbes is required to determine how the great variety of seaweeds consumed by marine fishes are digested and their nutrients assimilated. Extensive evidence shows that, as in plant digestion by terrestrial herbivores, gut microbes play a role in algal digestion in many herbivorous fishes (Rimmer and Wiebe 1987; Sutton and Clements 1988; Clements 1991; Seeto et al. 1996; Choat et al. 2002; Mountfort et al. 2002; Skea et al. 2005). The types of algal cell breakage mechanisms in herbivorous fishes (Lobel 1981) were expanded by Horn (1989) to include fermentative digestion by microbial symbionts in a hindgut chamber. However, recent evidence clearly reveals that the rate of production and levels of fermentation end-products can be equally high in undifferentiated digestive tract regions of herbivorous fishes (Clements and Choat 1997; Mountfort et al. 2002).

Several studies reported diverse populations of microbes and high concentrations of short-chain fatty acids (SCFAs) in the digestive tract of a variety of herbivorous fishes, including relatives of zebraperch in the genus Kyphosus (Rimmer and Wiebe 1987; Kandel et al. 1994; Clements and Choat 1995). Clements and Choat (1997) concluded that high levels of SCFAs and a diet largely of recalcitrant brown algae suggested a significant role for microbial fermentation in the diet of K. bigibbus,Kyphosus sydneyanus, and K. vaigiensis. In contrast to their findings in kyphosids, Clements and Choat (1997) reported that the digestive tracts of girellids contained chlorophyte and rhodophyte species that should be digestible by endogenous enzymes, as well as high levels of detritus and animal matter, and low levels of SCFAs. The authors concluded that microbial fermentation is unlikely to be important in these fishes. Mountfort et al. (2002) were the first to report acetate uptake rates across the gut wall of temperate marine herbivorous fishes. The ability of herbivorous fishes to use acetate as an energy source (Clements et al. 1994), combined with reported uptake rates, supports the view that SCFAs, particularly acetate, constitute an important source of energy for herbivorous fishes.

Numerous studies have used pure-culture isolation techniques to characterize the gut microbiota of herbivorous fishes (Sutton and Clements 1988; MacCormack and Fraile 1990; Luczkovich and Stellwag 1993). Because these methods select for certain organisms, they are inadequate for studying the microbial ecology of a natural system (Amann et al. 1995). This prompted us to analyze $16 \mathrm{~S}$ rDNA as a means of assessing microbial diversity in the zebraperch gut. Several investigators have used 16S rDNA to infer phylogeny of as yet unculturable microbes (Giovannoni et al. 1990; Woese et al. 1990; DeLong et al. 1993). Recently, these techniques have been applied to defining microbial populations in the digestive tracts of animals (Paster et al. 1996; Wilson and Blitchington 1996; Whitford et al. 1998). According to Fuhrman et al. (1994), DNAbased analysis of microbial communities can achieve four goals: (1) create a list of "what is there," (2) quantify the abundance of members from the list, (3) compare microbial communities from different samples, and (4) detect potentially important community members.

According to Choat and Clements (1998), the building blocks of nutritional ecology for any animal are (1) details of food composition, (2) alimentary tract anatomy, and (3) mechanisms involved in digestion (including the identification of novel mechanisms). Such an approach might provide a framework for developing hypotheses to explain the evolution of herbivore structural features (Choat and Clements 1998). Previous work on zebraperch feeding and digestion by Sturm and Horn (1998) provided the background for our study of the gut microbiota of this herbivorous fish species.

The purpose of the present study was to test the hypothesis that the zebraperch intestine houses resident, fermentative bacteria capable of digesting algal polysaccharides thus aiding in the digestive processes of the fish. We used microscopy and molecular techniques to study the distribution and identity of zebraperch gut microbiota and any evidence of SCFAs in the HC and other parts of the intestine that would be indicative of microbial fermentation.

\section{Materials and methods}

\section{Zebraperch capture and processing}

Eight zebraperch ranging in standard length from 135 to $365 \mathrm{~mm}$ and weighing from 100 to $880 \mathrm{~g}$ were used for pure-culture isolation of bacteria, microscopic observations, and SCFA analyses. Four additional zebraperch (ranging in SL from 280 to $365 \mathrm{~mm}$ ) were used exclusively for bacterial DNA isolation and 16S rDNA analysis. Zebraperch were either speared or netted in shallow waters $(<10 \mathrm{~m})$ off Santa Catalina Island $\left(33^{\circ} 19^{\prime} 42^{\prime \prime} \mathrm{N}\right.$; $\left.118^{\circ} 18^{\prime} 37^{\prime \prime} \mathrm{W}\right)$ in southern California during the months of April through July between 1995 and 2001, and all fish used in the study had an intact digestive tract. Fish that were netted were killed with a blow to the head. All zebraperch were placed on ice for the 4$6 \mathrm{~h}$ required for transport to the lab for processing.

Sterile surgical clamps were used to separate specific digestive tract regions (Fig. 1): region 1-100 mm posterior to the pyloric caeca; region 2-immediately anterior to the hindgut; and region $\mathrm{HC}$ - the hindgut and caecum. The zebraperch gut tract is described in greater detail in Sturm and Horn (1998). The clamped regions were then cut with sterile scissors and removed. Gut contents from the three digestive tract regions were gently squeezed into separate, sterile, pre-weighed and post-weighed vials.

Microbe cell counts and morphological diversity

Aliquots of the gut contents from the eight fish were placed into pre-weighed vials of $4 \%$ formalin buffered 
Fig. 1 a Hermosilla azurea: Zebraperch gut anatomy and regions designated for sampling (see Materials and methods for descriptions). Arrow indicates hindgut caecum $(H C)$.

bEnlarged image of $\mathrm{HC}$ region

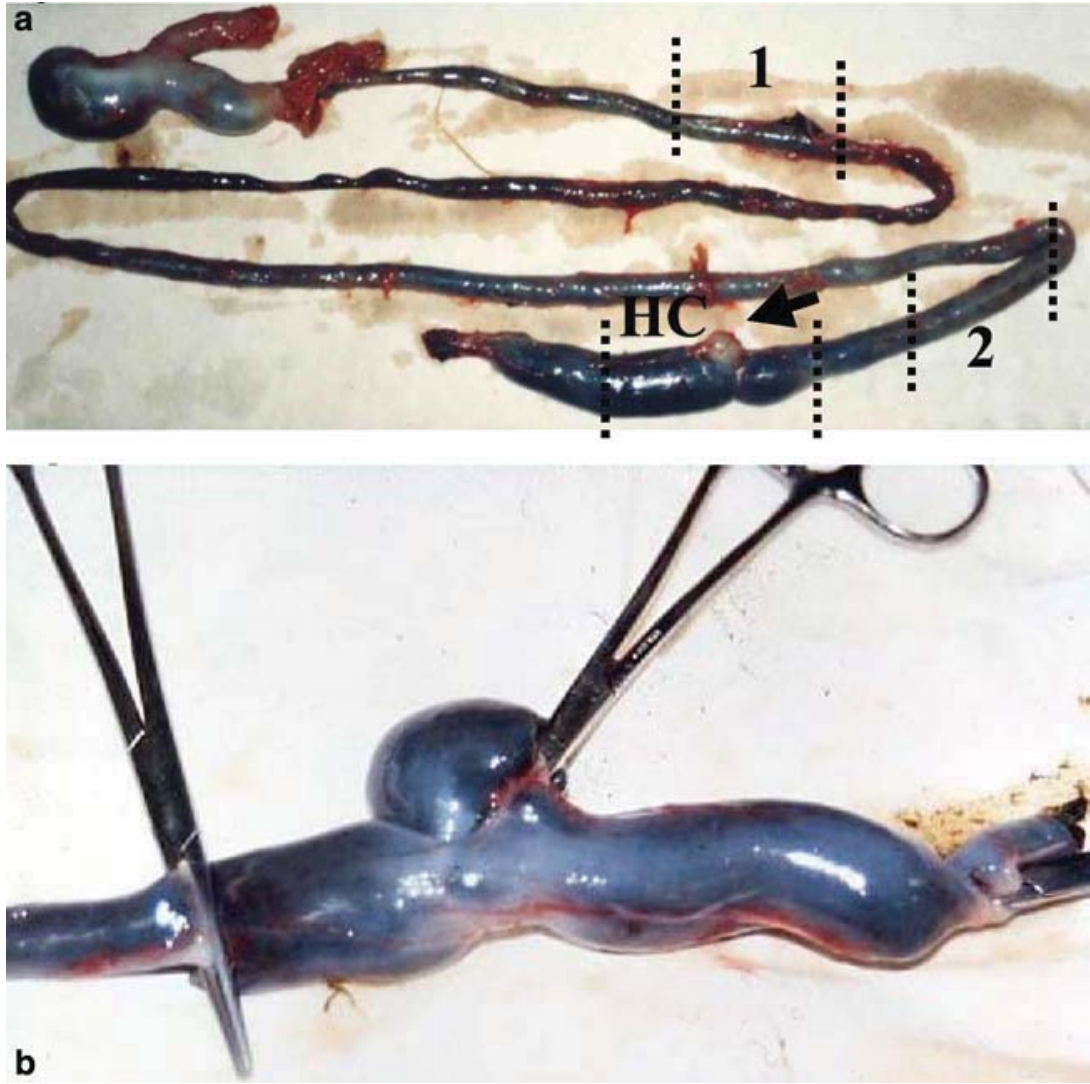

with $10 \mathrm{mM}$ Tris (pH 8) and stored at $4^{\circ} \mathrm{C}$ until used. These aliquot samples were vortexed, filtered $(0.22 \mu \mathrm{m}$ black polycarbonate filters; Poretics, Livermore, California, USA), stained with $0.1 \%$ acridine orange (three drops $\mathrm{ml}^{-1}$ filtered), and analyzed by epifluorescence microscopy (Hobbie et al. 1977). Ten random fields were counted per slide, and the bacterial count per gram wet-weight of gut contents was estimated according to a standard formula (Poretics). Microbes in ten random fields were categorized according to their morphology (small rods and vibrioid, 1-10 $\mu \mathrm{m}$; large rods, $>10 \mu \mathrm{m}$; cocci, spirals, and lampropredia-like) as described by Rimmer and Wiebe (1987). Cell size was measured by stage and ocular micrometers.

Microbial attachment to intestinal epithelium

Hindgut caecum tissue was placed in buffered seawater (0.1 M cacodylate, $0.17 \mathrm{M} \mathrm{NaCl}, \mathrm{pH}$ 7.2) and stored overnight at $4^{\circ} \mathrm{C}$. The tissue was then minced into $1-\mathrm{mm}^{3}$ pieces in cold $0.2 \mathrm{M}$ cacodylate and $0.34 \mathrm{M} \mathrm{NaCl}$ ( $\mathrm{pH} 7.2)$, transferred to primary fixative $(2.5 \%$ glutaraldehyde and $1.6 \%$ formalin in $0.2 \mathrm{M}$ cacodylate and $0.34 \mathrm{M} \mathrm{NaCl}, \mathrm{pH} 7.2$ ) for $1.5 \mathrm{~h}$ at $4^{\circ} \mathrm{C}$, and then transferred to $1 \%$ osmium tetroxide for $1 \mathrm{~h}$ at room temperature. The tissue was dehydrated in a graded ethanol series $(30,50,70,85$, and $100 \% ; 5$ to $10 \mathrm{~min}$ each) followed by propylene oxide $(100 \%)$ prior to infiltration with polypropylene/plastic $(1: 1,2 \mathrm{~h})$.
Dehydrated tissue was embedded in $100 \%$ plastic, sectioned, and viewed in the TEM (Hitachi H-7000).

\section{SCFA analysis}

One-milliliter aliquots from three gut content samples (excluding the stomach) of eight fish were placed into individual, pre-weighed $1.5 \mathrm{ml}$ cryovial tubes and each was acidified with two drops of concentrated sulfuric acid to arrest microbial activity. SCFA diversity and concentration were determined by high-performance liquid chromatography (HPLC). Aliquots of $200 \mu \mathrm{l}$ of acidified samples were placed in polypropylene tubes with $10 \mathrm{mg}$ sodium carbonate and centrifuged at $5000 \mathrm{~g}$ for $4 \mathrm{~min}$. The supernatants were twice extracted with $1.0 \mathrm{ml}$ of $\mathrm{CH}_{2} \mathrm{Cl}_{2}$ to remove lipids, which may interfere with SCFA analysis. Following the extractions, the volume was reduced under vacuum to $0.5 \mathrm{ml}$. Supernatants were filtered through a $0.22-\mu \mathrm{m}$ teflon filter for direct injection into the HPLC column. Analyses were performed on a Shimadzu Model 460 HPLC system equipped with UV detector, and detection was performed at $210 \mathrm{~nm}$. The analytical column $(25 \times 4.5 \mathrm{~cm})$ was an octadecyl silane 5- $\mu \mathrm{m}$ particle column (Axxion, Moorpark, California, USA). The mobile phase consisted of two solvents: A 95\% water, 5\% acetonitrile, $0.004 \mathrm{M}$ tetrabutyl ammonium phosphate ( $\mathrm{pH}$ 3.6); and B 5\% water, $95 \%$ acetonitrile, $0.004 \mathrm{M}$ tetrabutyl ammonium phosphate $(\mathrm{pH}$ 3.6). Both solvents were 
filtered and degassed under vacuum. The $10 \mathrm{~min}$ run consisted of a linear gradient of 15 to $65 \%$ B at a flow rate of $1 \mathrm{ml} \mathrm{min}^{-1}$. Peaks were identified and quantified using external standards (Sigma, St. Louis, MO, USA). For comparison purposes, two sets of samples were analyzed by gas-liquid chromatography according to the procedure of Clements et al. (1994).

\section{S rDNA analysis of microbial diversity}

\section{$D N A$ extraction and PCR}

Aliquots of hindgut contents of four fish were transferred to sterile, pre-weighed tubes containing $25 \mathrm{ml}$ of lysis buffer (40 mM EDTA, $50 \mathrm{mM}$ Tris, pH 8.3, $0.75 \mathrm{M}$ sucrose), vortexed, post-weighed, and stored at $-80^{\circ} \mathrm{C}$ until used. Each gut sample was vortexed for up to $50 \mathrm{~min}$ to release debris-associated microbial cells and then centrifuged at $1,500 \mathrm{~g}$ for $10 \mathrm{~min}$ to remove debris. The supernatant was placed in a round-bottom $50 \mathrm{ml}$ tube and centrifuged at $16,700 \mathrm{~g}$ for 5 min (Beckman model J2-HS with JA-17 rotor) to sediment bacteria. The resulting cell pellet was resuspended in $600 \mu \mathrm{l}$ of fresh lysis buffer and transferred to a microcentrifuge tube. An aliquot $(0.5-5 \mu \mathrm{l})$ of the cell suspension was prepared for direct-count analysis to determine the cell concentration.

Lysozyme was added to the cell suspensions to achieve a final concentration of $4 \mathrm{mg} \mathrm{ml}^{-1}$. The samples were then vortexed and incubated at $37^{\circ} \mathrm{C}$ for $1 \mathrm{~h}$. Sodium dodecyl sulfate solution was added to a final concentration of $2 \%$, and proteinase $\mathrm{K}$ was added to obtain a final concentration of $4 \mathrm{mg} \mathrm{ml}^{-1}$ in each sample. The samples were inverted by hand several times then incubated at $55^{\circ} \mathrm{C}$ for $30-60 \mathrm{~min}$. A $20 \mu \mathrm{l}$ aliquot was removed from each lysate for direct-count analysis to determine whether intact cells remained. If intact cells remained, the sample was returned to the $55^{\circ} \mathrm{C}$ water bath and cell lysis monitored by direct-count analysis at 15 min intervals until lysis was $>90 \%$ complete as determined by direct counts.

An equivalent volume of buffered phenol ( $\mathrm{pH} 8$; Fisher Scientific, Pittsburgh, Pennsylvania, USA) was added to each sample, mixed by inversion, and then centrifuged at $10,000 \mathrm{~g}$ for $5 \mathrm{~min}$. The resulting aqueous (top) layer was removed to a separate sterile microfuge tube, extracted with an equivalent volume of phenol/chloroform/isoamyl alcohol (24:24:1; pH 8), and centrifuged at 10,000 $g$ for $5 \mathrm{~min}$. Each subsequent aqueous layer was placed in a separate tube, extracted with chloroform/isoamyl alcohol (24:1), and centrifuged at $10,000 \mathrm{~g}$ for $5 \mathrm{~min}$ for a total of three extractions. The final aqueous layer was removed to a sterile tube and to the tube were added 1/10 volume of $3 \mathrm{M}$ sodium acetate ( $\mathrm{pH}$ 5.2) and two volumes of cold absolute ethanol. Samples were stored at $-20^{\circ} \mathrm{C}$ overnight and then centrifuged at high speed for $15 \mathrm{~min}$ in a microcentrifuge (Eppendorf model 5415C). The resulting DNA pellets were washed twice in cold $80 \%$ ethanol
( 2 min each wash) and centrifuged at 1,500 $\mathrm{g}$ for $5 \mathrm{~min}$. The ethanol was pipetted off, and tubes containing DNA pellets were inverted for $5 \mathrm{~min}$ to drain off any remaining ethanol. DNA pellets were then resuspended in $100 \mu \mathrm{l}$ of TE buffer (10 mM Tris- $\mathrm{HCl}$ and $1 \mathrm{mM}$ EDTA, pH 8). DNA was further purified prior to PCR amplification using Microspin S-400 HR sephacryl columns (Pharmacia Biotech, Piscataway, NJ, USA) according to manufacturer's specifications.

Ribosomal DNA was amplified by PCR using GeneAMP PCR reagents (Perkin-Elmer, Boston, MA, USA) according to manufacturer's specifications. Reaction mixtures contained 1.85-2.0 mM $\mathrm{MgCl}_{2}$, $10 \mathrm{mM}$ Tris- $\mathrm{HCl}$, pH 8.3, $50 \mathrm{mM} \mathrm{KCl}, 200 \mu \mathrm{M}$ deoxynucleotide triphosphates, 2.5 units of Thermus aquaticus DNA polymerase, $0.2 \mu \mathrm{M}$ of each oligonucleotide primer, and $10 \mathrm{ng}$ of DNA template. Oligonucleotide universal primers used were 1492R (5'-GGT TAC CTT GTT ACG ACT T-3'; bacterial reverse primer), 27F (5'-AGA GTT TGA TCC TGG CTC AG-3'; bacterial forward primer), $21 \mathrm{~F}$ ( $5^{\prime}$-TTC CGG TTG ATC CYG CCG GA-3'; archaeal forward primer), and 958R (5'-TCC GGC GTT GAM TCC AAT T-3'; archaeal reverse primer). Thermal cycling was performed as follows: denaturation at $92^{\circ} \mathrm{C}$ for $1.5 \mathrm{~min}$, annealing at $55^{\circ} \mathrm{C}$ for $1.5 \mathrm{~min}$, and extension at $72^{\circ} \mathrm{C}$ for $1.5 \mathrm{~min}$ for a total of 40 cycles. PCR products were checked for appropriate size $(1.5 \mathrm{kbp})$ by electrophoresis on a $1.2 \%$ agarose gel and stained with ethidium bromide.

\section{$16 \mathrm{~S}$ rDNA cloning}

PCR fragments were ligated into PCR2.1 TOPO vector and transformed into TOP10 competent cells according to the TOPO TA Cloning Kit protocol (Invitrogen, Carlsbad, CA, USA). From each transformation mixture, 50- and 200- $\mu$ l aliquots were spread on LuriaBertani (LB) agar containing $50 \mu \mathrm{g} \mathrm{ml}^{-1}$ ampicillin and $40 \mu \mathrm{l}$ of 5-bromo-4-chloro-3-indolyl- $\beta$-D-galactoside (Xgal; $40 \mathrm{mg} \mathrm{ml}^{-1}$ stock). Plates were incubated at $37^{\circ} \mathrm{C}$ for $18-24 \mathrm{~h}$ then placed at $4^{\circ} \mathrm{C}$ for $2-3 \mathrm{~h}$ for color development to distinguish white, insert-containing colonies from blue, noninsert-containing colonies. Insert-containing clones were inoculated into $3 \mathrm{ml}$ of LB broth containing $50 \mu \mathrm{g} \mathrm{ml}^{-1}$ ampicillin and grown overnight in a shaking $37^{\circ} \mathrm{C}$ incubator. Plasmid DNA was extracted from the cells using the Wizard SV Plus miniprep kit according to manufacturer's specifications (Promega, Madison, WI, USA). An aliquot of each plasmid preparation was separated on a $0.7 \%$ agarose gel using a supercoiled DNA ladder as a standard to reveal, based on size, which plasmids contained the desired insert.

\section{RFLP analysis}

Plasmid DNA containing a $16 \mathrm{~S}$ rDNA insert was isolated from each clone using the Wizard SV Plus 
miniprep kit. An aliquot of each plasmid preparation containing about $200 \mathrm{ng}$ of DNA was mixed with universal bacterial primers in a PCR. The resulting $16 \mathrm{~S}$ rDNA PCR products were then digested with restriction endonucleases to compare their restriction patterns. For restriction digests, $6 \mu \mathrm{l}$ of PCR product were mixed with $1 \mu \mathrm{l}$ of 10X Buffer B (Promega) and 3 units each of HinFI (Promega) and RsaI (Promega) to a final volume of $10 \mu \mathrm{l}$. The mix was incubated in a $37^{\circ} \mathrm{C}$ water bath for $1.5 \mathrm{~h}$. Reactions were separated in a $4 \%$ Metaphor (Biowhittaker, Walkersville, MD, USA) agarose gel. Gel images were viewed with a BioRad multi-imager, and the resulting bands were sized using BioRad Quantityone software. Unique restriction patterns were identified and placed in separate operational taxonomic units (OTUs). An estimate of coverage (C) within samples was calculated using the equation $C=1-(n / N) \times 100$, where $n$ is the number of unique clones and $N$ is the total number of clones examined (Ravenschlag et al. 1999).

DNA sequencing and analysis

Cloned 16S rDNA representing each of the seven most common OTUs was sequenced at the California State University, Northridge, sequencing facility. DNA sequences ranging from 656 to 1408 base pairs were submitted to the GenBank database, and accession numbers for each are reported in the Results section. These sequences were compared to $16 \mathrm{~S}$ rDNA sequences in public databases using the BLAST algorithm (Altschul et al. 1990). Closely matching sequences were aligned and phylogenetic trees based on the neighbor-joining algorithm were constructed using MacVector 8.0 Software (Accelrys, San Diego, CA, USA).

\section{Results}

Direct microbial counts and morphological diversity

Bacterial cell counts consistently increased from gut region 1 to region $\mathrm{HC}$ (Fig. 2). Average cell counts per gram wet-weight of gut contents were as follows: region $1: 1.86 \times 10^{8}$ (range: $7.2 \times 10^{7}-4.8 \times 10^{8}$ ), region $2: 4.24 \times 10^{9}$ (range: $5.43 \times 10^{7}-1.76 \times 10^{10}$ ), and region HC: $1.22 \times 10^{10}$ (range: $\left.1.95 \times 10^{9}-3.3 \times 10^{10}\right)$. Short rods $(<10 \mu \mathrm{m})$ and vibrioid cells were predominant in regions 2 and HC. Spiral-shaped bacteria were seen in relatively low concentrations in all gut regions. Large rods ranging in length from 15 to $65 \mu \mathrm{m}$ and in width from 0.5 to $4 \mu \mathrm{m}$ were observed in low concentrations in regions 1 and 2, but were not detected in $\mathrm{HC}$ contents (Table 1).

\section{Microbial attachment to intestinal epithelium}

Observation using TEM revealed bacteria adherent to the HC epithelium (Fig. 3), to each other, or to ingested
Fig. 2 Hermosilla azurea: Mean direct counts $( \pm \mathrm{SE})$ of bacterial cells (per gm wet-weight of gut contents) from three regions of zebraperch digestive tract. Vertical lines on bars represent SEM ( $n=8$ fish)

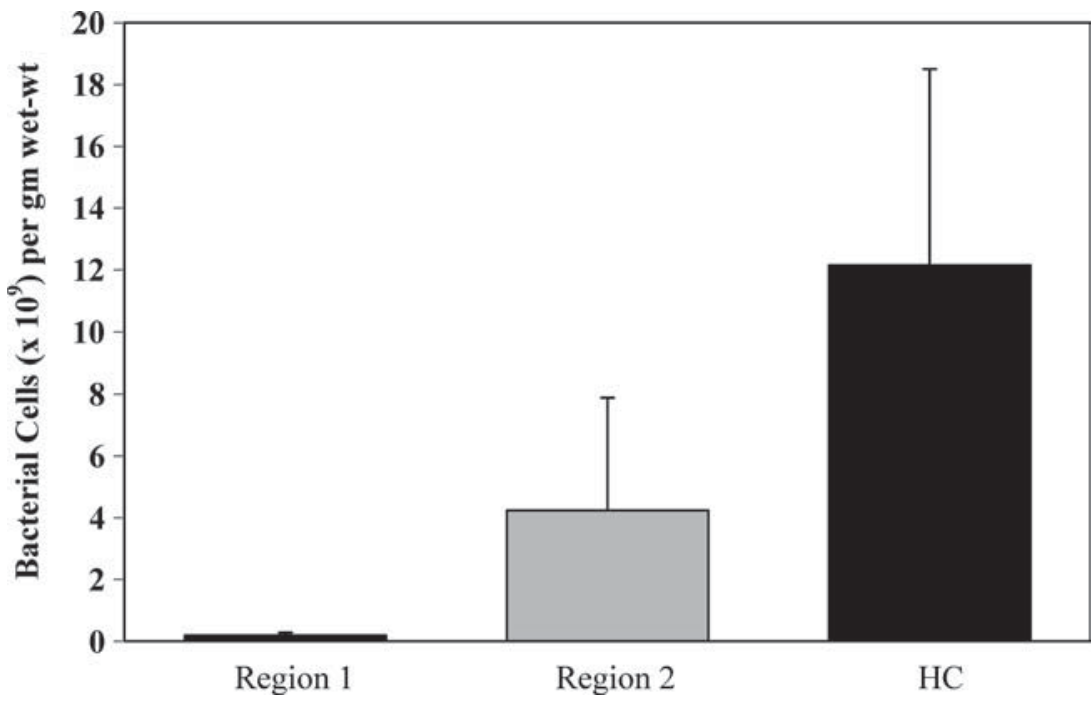

Table 1 Hermosilla azurea: Bacterial morphological diversity in three zebraperch gut regions

\begin{tabular}{llllll}
\hline Region & $\begin{array}{l}\text { Rod } \\
(>10 \mu \mathrm{m})\end{array}$ & $\begin{array}{l}\text { Rod/vibrioid } \\
(<10 \mu \mathrm{m})\end{array}$ & Coccus & Spiral & Lampropedia-like \\
\hline 1 & $3.4(0-12)$ & $37(11-50)$ & $47(12-64)$ & $12.6(0-53)$ & 0 \\
2 & $3.9(0-13)$ & $47.7(9-58)$ & $28.4(8-60)$ & $10.1(1-23)$ & 0 \\
HC & 0 & $63(36-93)$ & $34.5(9-49)$ & $1.5(0-7)$ & $1(0-3)$ \\
\hline
\end{tabular}

Data are shown as average percentage of each cell morphology followed by the range of percentages in parentheses $(n=8$ fish) 
algal components. Microbes were apparently attached to gut tissue by exopolymeric substances.

\section{SCFA analysis}

In order of abundance, the SCFAs identified in the gut from regions 1 through $\mathrm{HC}$ were acetate, propionate, valerate, butyrate, and isobutyrate. The ratio of relative percentages of these five SCFAs in the $\mathrm{HC}$ region was approximately 70:18:6:4:2, respectively. The predominance of acetate and propionate was consistent along the digestive tract of each fish sampled. In all fish, total SCFA levels increased from region 1 to $\mathrm{HC}$ (Table 2). The average ratio of total SCFAs from region 1 , region 2 , and $\mathrm{HC}$ was $1: 1: 2.3$. The average 2.3-fold increase in SCFA levels from region 2 to $\mathrm{HC}$ corresponded to about a threefold increase in microbial cell numbers.

Molecular phylogeny of gut microbes

The hindguts of four zebraperch each contained 17$20 \mathrm{~g}$ of material and yielded $20-70 \mu \mathrm{g}$ of DNA. When an aliquot of this DNA was combined with universal archaeal primers in a PCR mixture, no amplified product was obtained. Universal bacterial primers, however, amplified $1.5 \mathrm{kbp}$ fragments of $16 \mathrm{~S}$ rDNA from the extracted DNA. A library of 430 clones (representing $74 \%$ coverage in the cumulative sample) was prepared from these PCR products. Restriction endonuclease digestion of these 430 cloned 16S rDNA fragments yielded 138 unique restriction patterns (OTUs). Of these, 32 OTUs were detected in more than one fish, and three (I, III, and IV) were present in all four fish (Table 3). The predominant OTU (I) comprised 167 clones and was most closely related to members of the genus Enterovibrio. All of the $16 \mathrm{~S}$ rDNA sequences shared 90-98\% identity along their entire length to their corresponding matches in the database. Variation in $16 \mathrm{~S}$ rDNA RFLP pattern (i.e. variation in the highest and lowest molecular weight band) was detected among the 167 clones. These variations were used to divide OTU I into seven subgroups (only the most abundant of these subgroups was sequenced). The $16 \mathrm{~S}$ rDNA sequence comparisons revealed that the next most predominant OTUs (IIVII) in zebraperch HC contents closely matched $\mathrm{Bac}$ teroides (OTU II), Faecalibacterium (OTU III), an asyet-uncultured deep-sea bacterium (OTU VI), and three OTUs classified as Desulfovibrio (OTUs IV, V, and VII; Table 4 and Fig. $4 \mathrm{a}-\mathrm{e}$ ). Of these genera, Enterovibrio,Faecalibacterium, and one of the three Desulfovibrio OTUs were detected in all four zebraperch sampled.
Fig. 3 Hermosilla azurea: Transmission electron micrograph of bacteria that appear to be attached to zebraperch hindgut epithelium (arrows) by an exopolymeric layer $($ bar $=0.5 \mu \mathrm{m})$

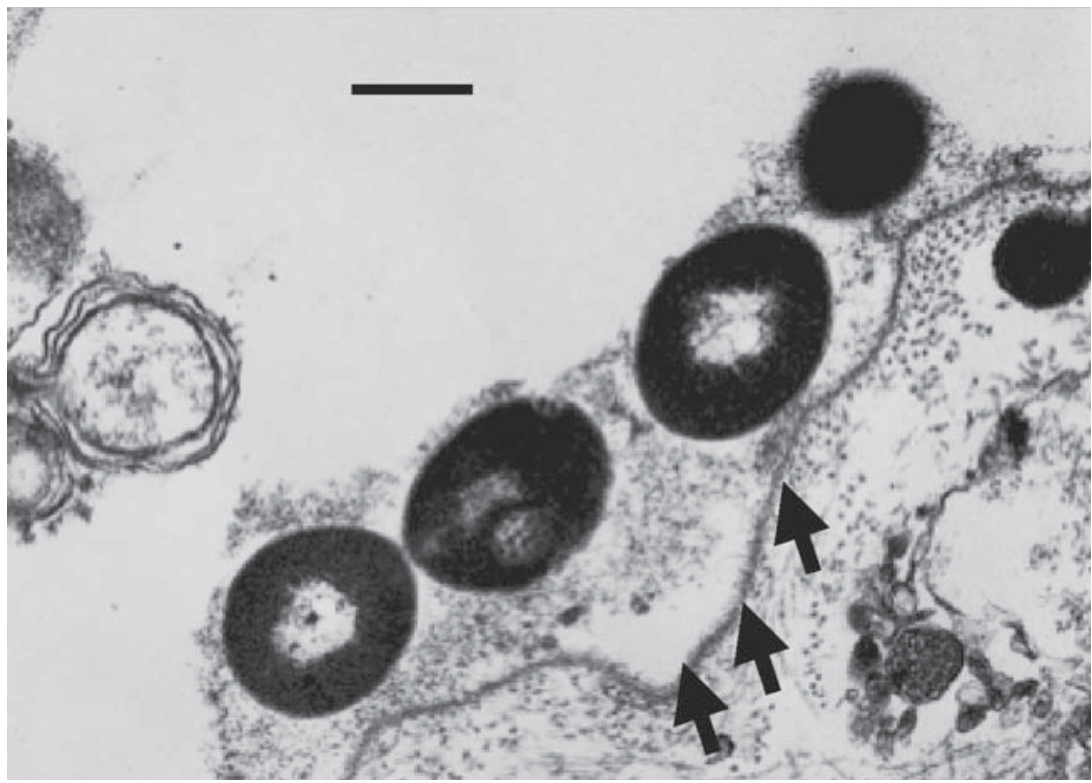

Table 2 Hermosilla azurea: Levels (mM) of five SCFAs in three digestive tract regions $(N=8$ fish)

Values are mean concentration $(\mathrm{mM}) \pm$ SEM

\begin{tabular}{llll}
\hline & Region 1 & Region 2 & HC \\
\hline SCFA type & & & \\
Acetate & $7.46 \pm 0.98$ & $7.26 \pm 0.66$ & $15.25 \pm 1.39$ \\
Propionate & $1.55 \pm 0.22$ & $1.78 \pm 0.27$ & $3.99 \pm 0.31$ \\
Valerate & $0.495 \pm 0.50$ & $0.315 \pm 0.26$ & $1.18 \pm 0.15$ \\
Butyrate & $0.433 \pm 0.20$ & $0.499 \pm 0.22$ & $0.798 \pm 0.12$ \\
Isobutyrate & $0.275 \pm 0.16$ & $0.212 \pm 0.04$ & $0.424 \pm 0.07$ \\
\hline
\end{tabular}


Table 3 Hermosilla azurea: Distribution of OTUs within the hindgut and caecum of four zebraperch

\begin{tabular}{ll}
\hline Fish & OTUs \\
\hline 1 & I(45), II (20), III(2), IV(8), V (10), VI (6), VII (2), VIII (7), IX (4), X (4), XI (2), XII (3), XIII (3), XIV (1), XV (1), XVI (2), \\
& XVII (1), XVIII (2) \\
2 & I(92), II (2), III(2), IV(1), VI (2), VII (3), IX (1), XI (2), XIV (1), XV (1), XVIII (1), XIX (1), XX (1) \\
3 & I(27), III(13), IV (2), XVIII (2), XIX (1), XXII (3), XXIII (3), XXIV (1) \\
4 & I(3), III(2), IV(1), VI (1), XVII (1), XX (1), XXIV (1), XXV (7), XXVI (2) \\
\hline
\end{tabular}

OTUs are presented as roman numerals followed by the number of clones that comprise the OTU from each fish (in parentheses). OTUs in bold were detected in all fish

\section{Discussion}

The results of this study showed clearly that the zebraperch harbors in its digestive tract a diverse and abundant microbial community that is most densely concentrated in the $\mathrm{HC}$ (hindgut and blind caecum). Our data show that (1) the variety and density of microbes increased from anterior to posterior in the intestine culminating in the $\mathrm{HC}$ region, (2) microbes were detected attached to intestinal epithelium and growing in intestinal contents, (3) SCFAs (mainly acetate) also increased posteriad with highest levels in the HC region, and (4) vibrioid cells and small rods predominated in the intestine based on direct observation and 16S rDNA analysis.

The fish possessed a gut microbiota in concentrations that were close to the average counts in $K$. sydneyanus (Rimmer and Wiebe 1987), another herbivorous kyphosid. Microbial counts increased significantly from anterior to posterior along the digestive tract in all eight zebraperch examined. These findings are consistent with the concept of a resident microbiota in fish guts (Rimmer 1986; Rimmer and Wiebe 1987; Clements 1991; Ringo et al. 2001) and support the conclusion of Liston (1957) that bacteria present in the intestines of marine fishes do not arise solely from mechanical transfer from the diet, but rather that conditions in the gut impose selective mechanisms that allow certain microbes to thrive.

Microscopic analysis of zebraperch gut contents revealed a morphologically diverse gut microbiota only broadly similar to those reported for other marine

Table 4 Hermosilla azurea: Identification of predominant OTUs based on $16 \mathrm{~S}$ rDNA in zebraperch hindgut and caecum contents

\begin{tabular}{llll}
\hline OTU & Genus & Frequency & GenBank accession no. \\
\hline I & Enterovibrio sp. & $167(4 / 4)$ & AY962592 \\
II & Bacteroides sp. & $22(2 / 4)$ & AY962593 \\
III & Faecalibacterium sp. & $19(4 / 4)$ & AY962594 \\
IV & Desulfovibrio sp. & $12(4 / 4)$ & AY962595 \\
V & Desulfovibrio sp. & $10(1 / 4)$ & AY962596 \\
VI & Unknown & $9(3 / 4)$ & AY962597 \\
VII & Desulfovibrio sp. & $5(2 / 4)$ & AY962598 \\
\hline
\end{tabular}

Frequency of each OTU is presented as the number of clones composing an OTU followed by number of fish ( $n=4$ examined) in which OTU was detected (in parentheses) herbivorous fishes. With the exception of region 1 , in which cocci were dominant, small rods and vibrioid cells were predominant along the digestive tract. Spirals and small rods $(<10 \mu \mathrm{m})$ were co-dominant in the caecal pouch of $K$. cornelii and $K$. sydneyanus (Rimmer and Wiebe 1987), and spirals also dominated posterior tract regions in the herbivorous odacid fish, Odax cyanomelas (Clements 1991). In contrast, spirals made up only $1.5 \%$ of zebraperch HC contents. Clements (1991) reported a steady increase in cocci toward the posterior part of the digestive tract of $O$. cyanomelas, a pattern not observed in zebraperch. Moreover, vibrioid cells appear to be absent in the gut contents of both $O$. cyanomelas (Clements 1991) and the two species of Kyphosus (Rimmer and Wiebe 1987). Differences in morphological diversity of gut microbes in the confamilial K. cornelii, K. sydneyanus, and zebraperch illustrate the diversity of microbes that may be recruited to establish a fermentative microbiota among species within the same family.

Several studies using TEM have demonstrated that fishes maintain resident microbial biotas. Ringo et al. (2001) concluded that microbes attached to the intestinal epithelium of Arctic char (Salvelinus alpinus) were resident. Similarly, our electron micrographs of the zebraperch $\mathrm{HC}$ epithelium revealed heavy colonization by diverse microbiota. In the zebraperch, many bacteria appeared to be attached to the gut wall via a common extracellular matrix, and some appeared to be dividing. Microbes attached to gill filaments of the turbot (Scopthalmus maximus) led Muddaris and Austin (1988) to conclude that these microbes were residents of the gills of this species.

The five SCFA types in zebraperch gut contents were also found in the related fishes $K$. sydneyanus, $K$. bigibbus, and K. vaigiensis (Clements and Choat 1997), although there were differences in the concentrations and proportions of SCFAs between the zebraperch and these other kyphosids. Acetate and propionate as the two most abundant SCFAs in three zebraperch digestive tract regions is similar to the SCFA profile reported for equivalent digestive tract regions in $K$. sydneyanus (Mountfort et al. 2002). However, unlike in zebraperch, valerate and isobutyrate were undetectable in anterior digestive tract regions of $K$. sydneyanus, $K$. bigibbus, and $K$. vaigiensis . Furthermore, butyrate was the secondmost abundant SCFA after acetate in region 4 (equivalent to region 2 in this study) in $K$. vaigiensis and 
Fig. 4 Hermosilla azurea: Phylogenetic tree showing the relationship of partial $16 \mathrm{~S}$ rDNA sequences from OTUs I-VII to a Vibrionaceae (OTU I); b Bacteroidetes (OTU II); c Clostridiales (OTU III); d Desulfovibrionales (OTUs IV, V, and VII);

e Enterobacteriaceae (OTU VI); Scale bars represent fixed nucleotide substitutions per sequence position. GenBank accession numbers follow each taxon name

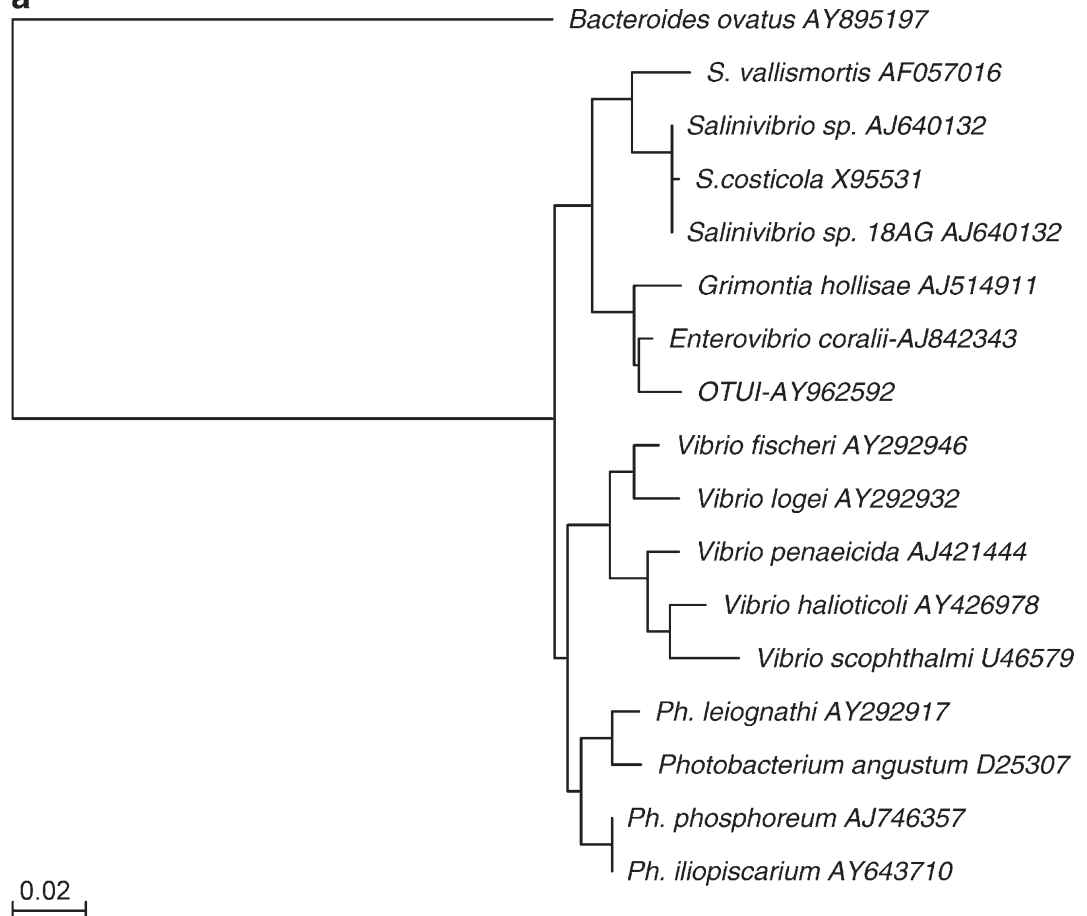

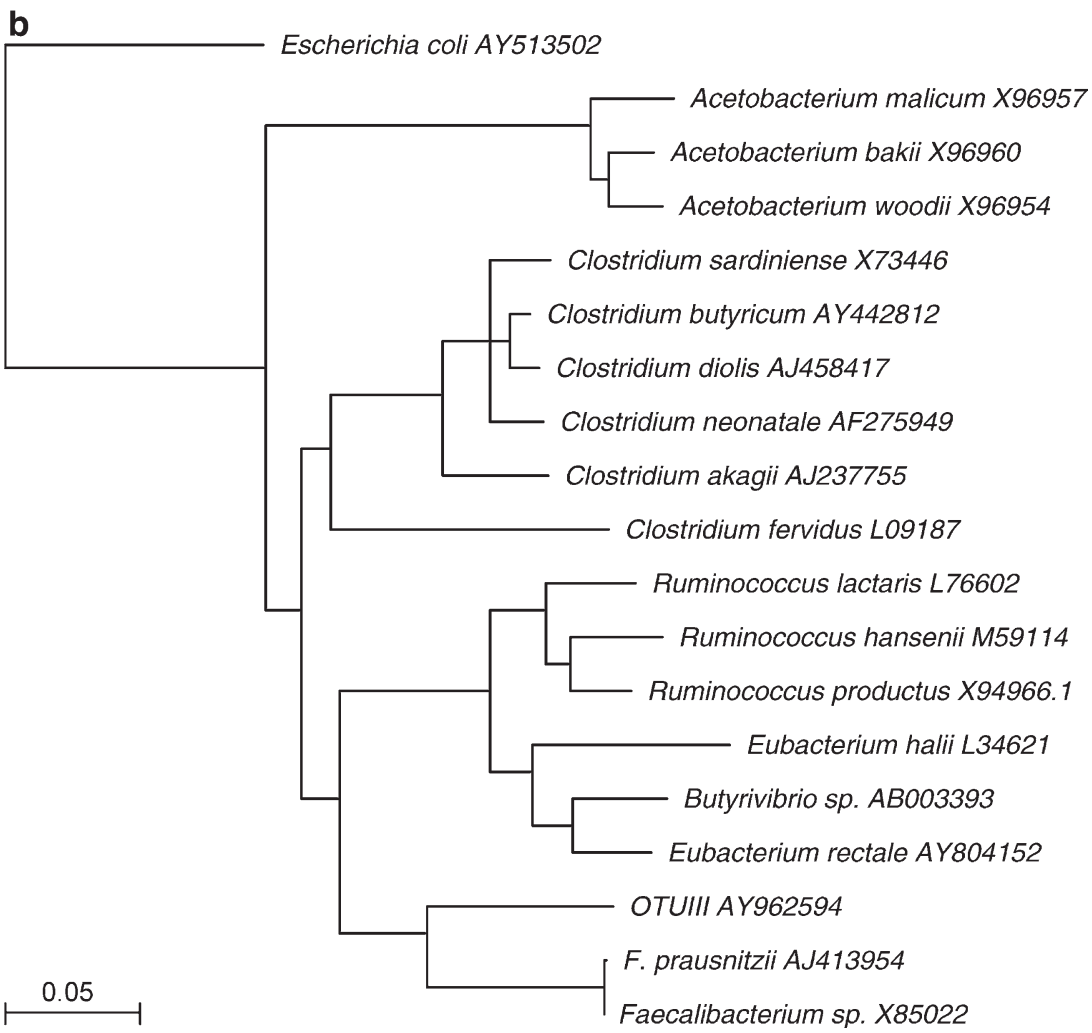

$K$. bigibbus, although acetate and propionate, respectively, were predominant in region 5 (equivalent to $\mathrm{HC}$ in this study) of these fishes (Clements and Choat 1997). Our finding that the relative proportions of all five
SCFAs detected in the zebraperch gut were similar along the tract suggests that (1) only specific substrates are available for fermentation within the gut, or that (2) a specific fermentative microbial consortium is established 
Fig. 4 (Contd.)
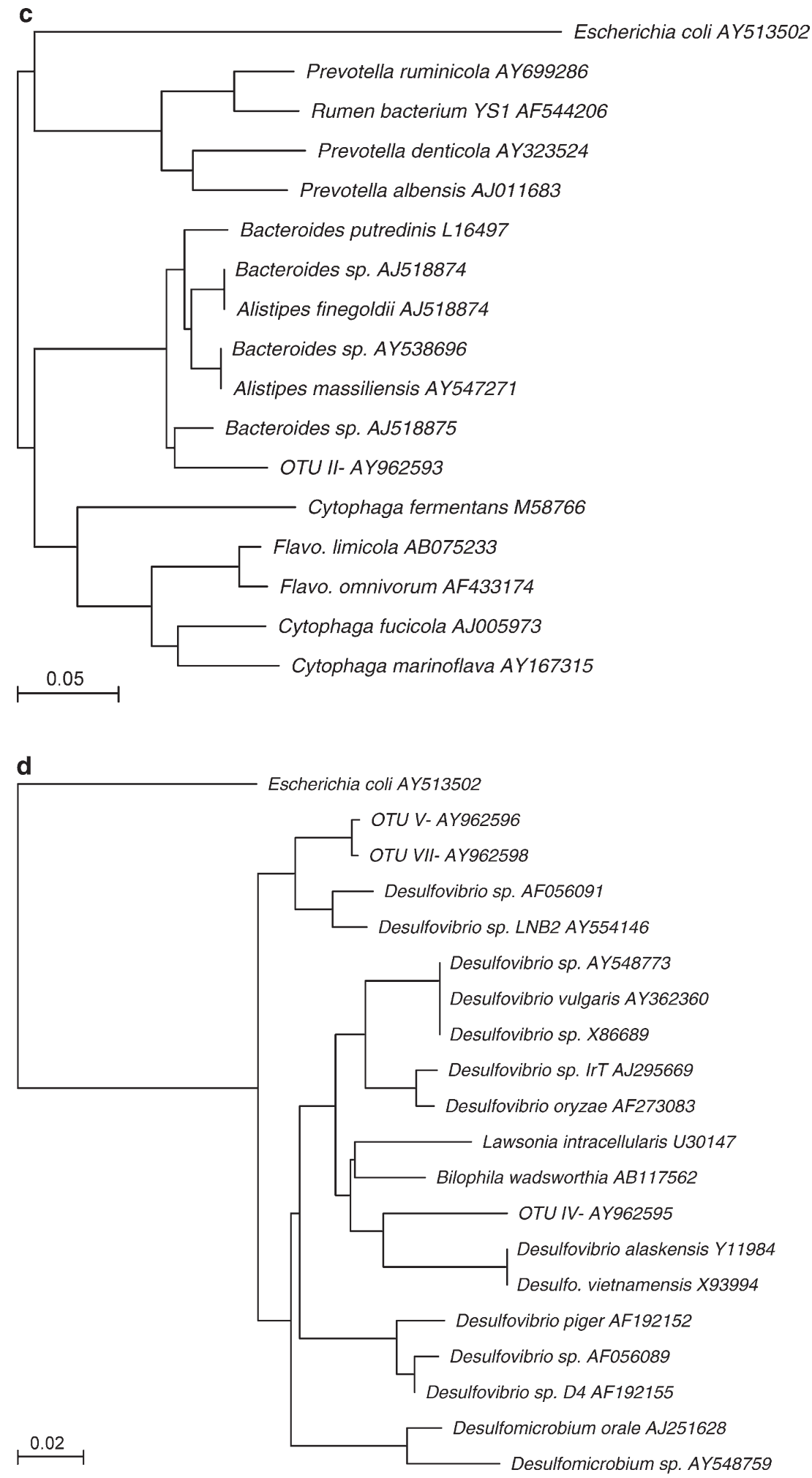

in anterior gut regions and then grows en route to the posterior regions. The predominance of red algae in the zebraperch diet (Sturm and Horn 1998) supports explanation (1). We used molecular phylogenetic analyses of anterior gut microbiota to resolve explanation (2) (see below).
The presence of SCFAs in zebraperch gut regions 1 and 2 suggests that fermentation begins in the anterior part of the intestine. The higher concentration of SCFAs in the zebraperch $\mathrm{HC}$ contents compared to that of anterior gut regions corresponds to elevated bacterial counts. This finding supports our conclusion that 
Fig. 4 (Contd.)

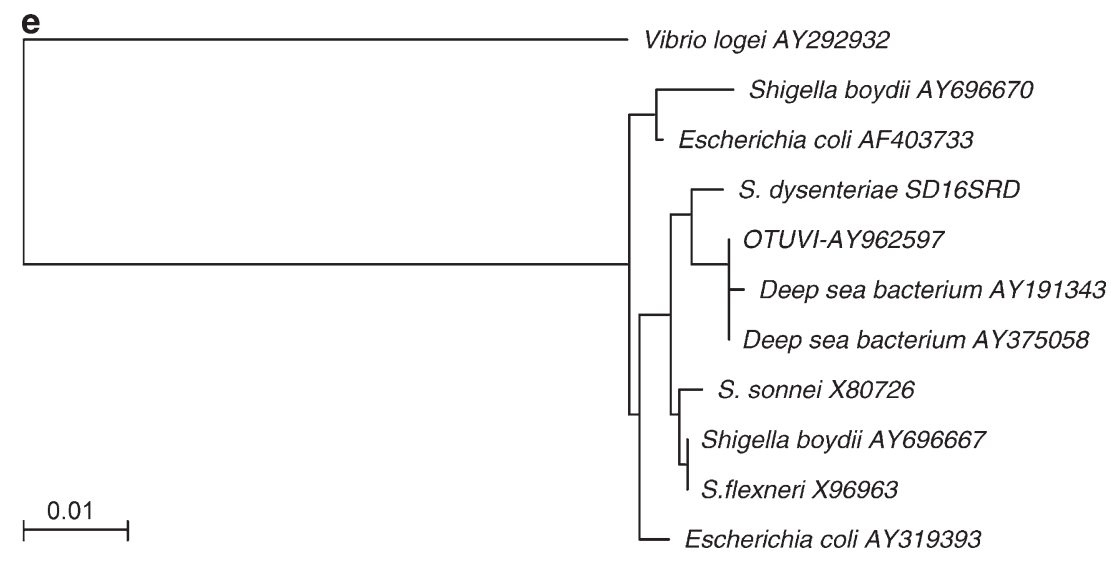

resident microbes are producing these end-products. At least two studies (Titus and Ahearn 1991; Mountfort et al. 2002) have shown that herbivorous fishes can absorb SCFAs from the gut lumen into the blood, while another work by Seeto et al. (1996) has shown that fishes have the capacity to use SCFAs as energy sources. The authors of each of these works concluded that SCFAs can contribute a significant proportion of the energy requirement of certain herbivorous fishes. Two findings, however, led Mountfort et al. (2002) to question the role of specialized gut architecture in fermentation: (1) highfermentation rates in Odax pullus and Aplodactylus arctidens, fishes with simple, undifferentiated hindgut regions, and (2) similar fermentation rates in the hindgut and an undifferentiated region just anterior to the hindgut in K. sydneyanus. These data are consistent with previous work in which SCFA levels in the differentiated hindgut and the region immediately anterior to the hindgut of three kyphosid species were similar (Clements and Choat 1997). The specific role for the zebraperch hindgut and caecum awaits studies designed to measure rates of SCFA production and uptake and to detect assimilated SCFAs in zebraperch tissues.

Our inability to culture $98 \%$ of the zebraperch gut microbiota (based on comparisons to direct counts) was the impetus to use a molecular phylogenetic approach to identify these bacteria. As much as $80 \%$ of the human gut microbiota have not been cultured, which likewise has prompted molecular phylogenetic studies to identify them (Wilson and Blitchington 1996; Suau et al. 1999). The four most common OTUs in zebraperch HC contents were closely related to the genera Enterovibrio (OTU I), Bacteroides (OTU II), Faecalibacterium (OTU III), and Desulfovibrio (OTU IV). The inability to detect Archaea in zebraperch $\mathrm{HC}$ contents may result from their absence or minor presence in this fish. Archaean prokaryotes, however, have been found in the gut contents of other marine fish species (Van der Maarel et al. 1998), and, therefore, further research may reveal their presence in zebraperch.

The term "gut group Vibrio" was introduced by Liston (1957) to indicate that vibrioid cells dominate the intestinal microbiota of marine fishes. Recent evidence supports the use of this terminology (see references in Hansen and Olafeson 1999). Clones composing OTU I are related to a recently described genus, Enterovibrio (Thompson et al. 2002), and grouped closest to E. coralii, an etiologic agent of coral bleaching (Fig. 4a; Thompson et al. 2005). A second member of the genus, Enterovibrio norvegicus, was isolated from the gut of healthy, cultured turbot larvae (Thompson et al. 2002). The detection of enterovibrios in healthy zebraperch and turbot suggests that they might be normal microbiota within many types of marine fish.

The second-most dominant OTU (II) in zebraperch $\mathrm{HC}$ contents grouped with members of the genera Alistipes and Bacteroides (Fig. 4b). Species in these genera (especially Bacteroides) are abundant in the digestive tract of vertebrates (Suau et al. 1999; Lu et al. 2003) where they have been linked to starch breakdown (Wang et al. 1999). Species of Bacteroides produce a variety of glucosidases, including $\beta$-1,3-glucosidase that can degrade laminarin, a polysaccharide of brown algae (Salyers et al. 1977), and $\alpha$ and $\beta-1,4$ and $-1,6$ xylosidase and glucosidase activities that are induced by the presence of hemicellulose (Reddy et al. 1984). Typical Bacteroides species found in mammals, however, do not survive long in oxygenated water (Kreader 1998; Bernhard and Field 2000). Therefore, the species we found might be uniquely adapted to periodic exposure to the marine environment.

Members of OTU III were most closely related to Faecalibacterium prausnitzii (Fig. 4c), formerly Fusobacterium prausnitzii (Duncan et al. 2002). Cells of $F$. prausnitzii are common gut residents of goldfish (Sugita et al. 1988), chickens (Lu et al. 2003), ruminants (Narayanan et al. 1997), and humans (Wilson and Blitchington 1996). The metabolic end-products of F. prausnitzii are lactate, butyrate, and formate (KuritaOchiai et al. 1998; see references in Suau et al. 1999; Duncan et al. 2002). The presence of butyrate and formate (data not shown) in zebraperch $\mathrm{HC}$ contents suggests that OTU III members might be important contributors to fermentation in zebraperch. In particular, their ability to produce high levels of butyrate (Duncan et al. 2002) might serve as an essential energy 
source for the intestinal epithelium (Tran et al. 1998). Acetate, which is abundant in zebraperch hindgut contents, is a substrate for butyrate formation by colonic bacteria such as $F$. prausnitzii (Duncan et al. 2004).

Desulfovibrio species (OTUs IV, V, and VII; Fig. 4d) are anaerobic, sulfate-reducing bacteria (SRB) that might have a nutritional role in mouse (Deplancke et al. 2000) and termite intestinal contents (Brune and Friedrich 2000). SRB are abundant components of mouse intestinal microbiota, accounting for $17-23 \%$ of the $16 \mathrm{~S}$ rDNA examined (Deplancke et al. 2000). The predominance of red algae in the zebraperch diet suggests that the most likely source of sulfate would be sulfated algal galactans (McCandless and Craigie 1979). Sulfomucins, such as those in the human intestine (Tsai et al. 1992), might be another source of sulfate in the zebraperch gut. According to Willis et al. (1996), species of Bacteroides release sulfate from sulfomucin and use the mucin component as a fermentable carbon and energy source. This activity results in elevated levels of SCFA and sulfate in the intestinal lumen. SCFAs could be absorbed by the zebraperch and used in conjunction with the released sulfate to support the growth of SRB. Mountfort et al. (2002), however, reported that $\mathrm{SRB}$ activity was an insignificant contributor to the fate of acetate in three species of marine herbivorous fishes from New Zealand waters. Additional research will be required to resolve the metabolic complexities within the zebraperch gut.

This study expands upon previous work by Sturm and Horn (1998) to advance our understanding of zebraperch nutritional ecology. The foundation is now laid for additional studies on gut microbiota composition and metabolism, SCFA yield, and SCFA uptake by host tissue to understand how the zebraperch gains adequate nutrition from its algal diet.

Acknowledgments We thank Captain J. Cvitanovich and the crew of the R.V. Yellowfin for their help in capturing fish. We also thank W. Van Antwerp for performing SCFA analyses, E. Sturm for leading several expeditions to collect fish, and E. DeLong for his generous donation of PCR primers. T. Parker, J. Ferreira, W. Katzenstein, C. Hamilton, D. Tessier, S. Ecker, J. Haygood, and D. Asher provided valuable assistance with fish collection and lab work. The Departmental Associations Council and the Department of Biological Science at California State University, Fullerton, provided financial support. All experiments herein comply with the laws of the United States of America.

\section{References}

Altschul SF, Gish W, Miller W, Meyers EW, Lipman DJ (1990) Basic local alignment search tool. J Mol Biol 215:403-410

Amann RI, Ludwig W, Schleiffer KH (1995) Phylogenetic identification and in situ detection of individual microbial cells without cultivation. Microbiol Rev 59:143-169

Bernhard AE, Field KG (2000) Identification of nonpoint sources of fecal pollution in coastal waters by using host-specific $16 \mathrm{~S}$ ribosomal DNA genetic markers from fecal anaerobes. Appl Environ Microbiol 66:1587-1594

Brune A, Friedrich MW (2000) Microecology of the termite gut: structure and function on a microscale. Curr Opin Microbiol 3:263-269
Choat JH, Clements KD (1998) Vertebrate herbivores in marine and terrestrial environments: a nutritional ecology perspective. Annu Rev Ecol Syst 29:375-403

Choat JH, Clements KD, Robbins WD (2002) The trophic status of herbivorous fishes on coral reefs. Mar Biol 140:613-623

Clements KD (1991) Endosymbiotic communities of two herbivorous labroid fishes, Odax cyanomelas and O. pullus. Mar Biol 109:223-229

Clements KD, Choat JH (1995) Fermentation in tropical marine herbivorous fishes. Physiol Zool 68:355-378

Clements KD, Choat JH (1997) A comparison of herbivory in the closely related marine fish genera Girella and Kyphosus. Mar Biol 127:579-586

Clements KD, Gleeson VP, Slaytor M (1994) Short-chain fatty acid metabolism in temperate marine herbivorous fish. J Comp Physiol B 168:61-72

DeLong EF, Franks DG, Alldredge AL (1993) Phylogenetic diversity of aggregate attached vs. free-living marine bacterial assemblages. Limnol Oceanogr 38:924-934

Deplancke B, Hristova KR, Oakley HA, McCracken VJ, Aminov R, Mackie RI, Gaskins HR (2000) Molecular ecological analysis of the succession and diversity of sulfate-reducing bacteria in the mouse gastrointestinal tract. Appl Environ Microbiol 66:2166-2174

Duncan SH, Hold GL, Harmsen HJM, Stewart CS, Flint HJ (2002) Growth requirements and fermentation products of Fusobacterium prausnitzii, and a proposal to reclassify it as Faecalibacterium prausnitzii gen. nov., comb. nov. Int J Syst Evol Microbiol 52:2141-2146

Duncan SH, Holtrop G, Lobley GE, Calder AG, Stewart CS, Flint HJ (2004) Contribution of acetate to butyrate formation by human faecal bacteria. Br J Nutr 91:915-923

Fuhrman JA, Lee SH, Masuchi Y, Davis AA, Wilcox RM (1994) Characterization of marine prokaryotic communities via DNA and RNA. Microb Ecol 28:133-145

Giovannoni SJ, Britschgi TB, Moyer CL, Field KG (1990) Genetic diversity in Sargasso Sea bacterioplankton. Nature 345:60-62

Hansen GH, Olafsen JA (1999) Bacterial interactions in early life stages of marine cold water fish. Microb Ecol 38:1-26

Hobbie JE, Jasper S, Daley RJ (1977) Use of nucleopore filters for counting bacteria by fluorescence microscopy. Appl Environ Microbiol 33:1225-1228

Horn MH (1989) Biology of marine herbivorous fishes. Oceanogr Mar Biol Annu Rev 27:167-272

Horn MH (1992) Herbivorous fishes: feeding and digestive mechanisms. In: John DM, Hawkins SJ, Price JH (eds) Plant-animal interactions in the marine benthos. Systematics association special, vol 46. Clarendon Press, Oxford, pp 339-362

Kandel JS, VanAntwerp W, Horn MH (1994) Volatile fatty acids in the hindguts of herbivorous fishes from temperate and tropical marine waters. J Fish Biol 45:527-529

Kreader CA (1998) Persistence of PCR-detectable Bacteroides distasonis from human feces in river water. Appl Environ Microbiol 64:4103-4105

Kurita-Ochiai T, Ochiai K, Fukushima K (1998) Volatile fatty acid, metabolic by-product of periodontopathic bacteria, induces apoptosis in WEHI 231 and RAJI B lymphoma cells and splenic B cells. Infect Immun 66:2587-2594

Liston J (1957) The occurrence and distribution of bacterial types on flatfish. J Gen Microbiol 16:205-216

Lobel PS (1981) Trophic biology of herbivorous fishes: alimentary pH and digestive capabilities. J Fish Biol 19:365-397

Lu J, Idris U, Harmon B, Hofacre C, Maurer JJ, Lee MD (2003) Diversity and succession of the intestinal bacterial community of the maturing broiler chicken. Appl Environ Microbiol 69:6816-6824

Luczkovich JJ, Stellwag EJ (1993) Isolation of cellulolytic microbes from the intestinal tract of the pinfish, Lagodon rhomboides: size-related changes in diet and microbial abundance. Mar Biol 116:381-388

MacCormack WP, Fraile ER (1990) Bacterial flora of newly caught Antarctic fish Notothenia neglecta. Polar Bio 10:413-417 
McCandless EL, Craigie JS (1979) Sulfated polysaccharides in red and brown algae. Ann Rev Plant Physiol 30:41-53

Mountfort DO, Campbell J, Clements KD (2002) Hindgut fermentation in three species of marine herbivorous fish. Appl Environ Microbiol 68:1374-1380

Muddaris M, Austin B (1988) Quantitative and qualitative studies of the bacterial microflora of turbot, Scopthalmus maximus, gills. J Fish Biol 32:223-229

Narayanan S, Nagaraja TG, Okwumabua O, Staats J, Chengappa MM, Oberst RD (1997) Ribotyping to compare Fusobacterium necrophorum isolates from bovine liver abscesses, ruminal walls, and ruminal contents. Appl Environ Microbiol 63:4671-4678

Paster BJ, Dewhirst FE, Cooke SM, Fussing V, Poulsen LK, Breznak JA (1996) Phylogeny of not-yet cultured spirochetes from termite guts. Appl Environ Microbiol 62:347-352

Penry DL, Jumars PA (1987) Modeling animal guts as chemical reactors. Am Nat 129:69-92

Ravenschlag K, Sahm K, Pernthaler J, Amann R (1999) High bacterial diversity in permanently cold marine sediments. Appl Environ Microbiol 65:3982-3989

Reddy NR, Palmer JK, Pierson MD, Bothast RJ (1984) Intracellular glycosidases of human colon Bacteroides ovatus B4-11. Appl Environ Microbiol 48:890-892

Rimmer DW (1986) Changes in diet and the development of microbial digestion in juvenile buffalo bream, Kyphosus cornelii. Mar Biol 92:443-448

Rimmer DW, Wiebe RJ (1987) Fermentative microbial digestion in herbivorous fishes. J Fish Biol 31:229-236

Ringo E, Lødemel JB, Myklebust R, Kaino T, Mayhew TM, Olsen RE (2001) Epithelium-associated bacteria in the gastrointestinal tract of Arctic charr (Salvelinus alpinus L.). An electron microscopical study. J Appl Microbiol 90:294-300

Salyers AA, Vercellotti JR, West SEH, Wilkins TD (1977) Fermentation of mucin and plant polysaccharides by strains of Bacteroides from the human colon. Appl Environ Microbiol 33:319-322

Seeto GS, Veivers PC, Clements KD, Slaytor M (1996) Carbohydrate utilization by microbial symbionts in the marine herbivorous fishes Odax cyanomelas and Crinodus lophodon. J Comp Physiol B 165:571-579

Skea GL, Mountfort DO, Clements KD (2005) Gut carbohydrases from the New Zealand marine herbivorous fishes Kyphosus sydneyanus (Kyphosidae), Aplodactylus arctidens (Aplodactylidae) and Odax pullus (Labridae). Comp Biochem Physiol B 140:259-269

Sturm EA, Horn MH (1998) Food habits, gut morphology and $\mathrm{pH}$, and assimilation efficiency of the zebraperch Hermosilla azurea, an herbivorous kyphosid fish of temperate marine waters. Mar Biol 132:515-522

Sturm EA, Horn MH (2001) Increase in occurrence and abundance of zebraperch (Hermosilla azurea) in the Southern California Bight in recent decades. Bull So Cal Acad Sci 100:170-174
Suau A, Bonnet R, Sutren M, Godon J-J, Gibson GR, Collins MD, Dore J (1999) Direct analysis of genes encoding 16S rRNA from complex communities reveals many novel molecular species within the human gut. Appl Environ Microbiol 65:47994807

Sugita H, Tsunohara M, Ohkoshi T, Deguchi Y (1988) The establishment of an intestinal microflora in developing goldfish (Carassisus auratus) of culture ponds. Microb Ecol 15:333-344

Sutton D, Clements KD (1988) Aerobic heterotrophic gastrointestinal microflora of tropical marine fishes. Proc Sixth Int Coral Reef Symp (Aust) 3:185-190

Thompson FL, Hoste B, Thompson CC, Goris J, Gomez-Gil B, Huys L, De Vos P, Swings J (2002) Enterovibrio norvegicus gen. nov., sp. nov., isolated from the gut of turbot (Scopthalmus maximus) larvae: a new member of the family Vibrionaceae. Int J Syst Evol Microbiol 52:2015-2022

Thompson FL, Thompson CC, Naser S, Hoste B, Vandemeulebroecke K, Munn C, Bourne D, Swings J (2005) Photobacterium rosenbergii $\mathrm{sp}$. nov. and Enterovibrio coralii $\mathrm{sp}$. nov., vibrios associated with coral bleaching. Int J Syst Evol Microbiol 55:913-917

Titus E, Ahearn GA (1991) Transintestinal acetate transport in a herbivorous teleost: anion exchange at the basolateral membrane. J Exp Biol 156:41-61

Tran CP, Familari M, Parker LM, Whitehead RH, Giraud AS (1998) Short-chain fatty acids inhibit intestinal trefoil factor gene expression in colon cancer cells. Am J Physiol Gastrointest Liver Physiol 275:G85-G94

Tsai HH, Sunderland D, Gibson GR, Hart CA, Rhodes JM (1992) A novel mucin sulphatase from human feces: its identification, purification, and characterization. Clin Sci 82:447-454

Van der Maarel MJ, Artz R, Haanstra R, Forney LJ (1998) Association of marine archaea with the digestive tracts of two marine fish species. Appl Environ Microbiol 64:2894-2898

Wang X, Conway PL, Brown IL, Evans AJ (1999) In vitro utilization of high-amylose maize (amylomaize) starch granules by human colonic bacteria. Appl Environ Microbiol 65:4848-4854

Whitford MF, Forster RJ, Beard CE, Gong J, Teather RM (1998) Phylogenetic analysis of rumen bacteria by comparative sequence analysis of cloned 16S rRNA genes. Anaerobe 4:153163

Willis CL, Cummings JH, Neale G, Gibson GR (1996) In vitro effects of mucin fermentation on the growth of human colonic sulphate-reducing bacteria. Anaerobe 2:117-122

Wilson KH, Blitchington RB (1996) Human colonic biota studied by ribosomal DNA sequence analysis. Appl Environ Microbiol 62:2273-2278

Woese CR, Kandler O, Wheelis M (1990) Towards a natural system of nomenclature of organisms: proposal for the domains Archaea, Bacteria, and Eucarya. Proc Natl Acad Sci (USA) $87: 4576-4579$ 